\title{
Disaster Metrics: A Comprehensive Framework for Disaster Evaluation Typologies-CORRIGENDUM
}

Diana F. Wong, MCP Nsg; Caroline Spencer, PhD; Lee Boyd, PhD; Frederick M. Burkle, Jr., MD, MPH; Frank Archer, MBBS, MPH

doi: 10.1017/S1049023X17006471 Published by Cambridge

University Press, 8 May 2017.

Keywords: disasters; evaluation; framework; typology; corrigendum
In Wong et al. (2017), the author name of Frederick M. Burkle Jr. was incorrectly listed as Frederick "Skip" Burkle Jr. in the original article. The original version of the article has since been updated to reflect the correct name and citation for this author.

Reference

Wong DF, Spencer C, Boyd L, Burkle FM Jr., Archer F. Disaster Metrics: A

Comprehensive Framework for Disaster Evaluation Typologies. Prehospital and Disaster

Medicine 2017; Forthcoming. doi: 10.1017/S1049023X17006471. 